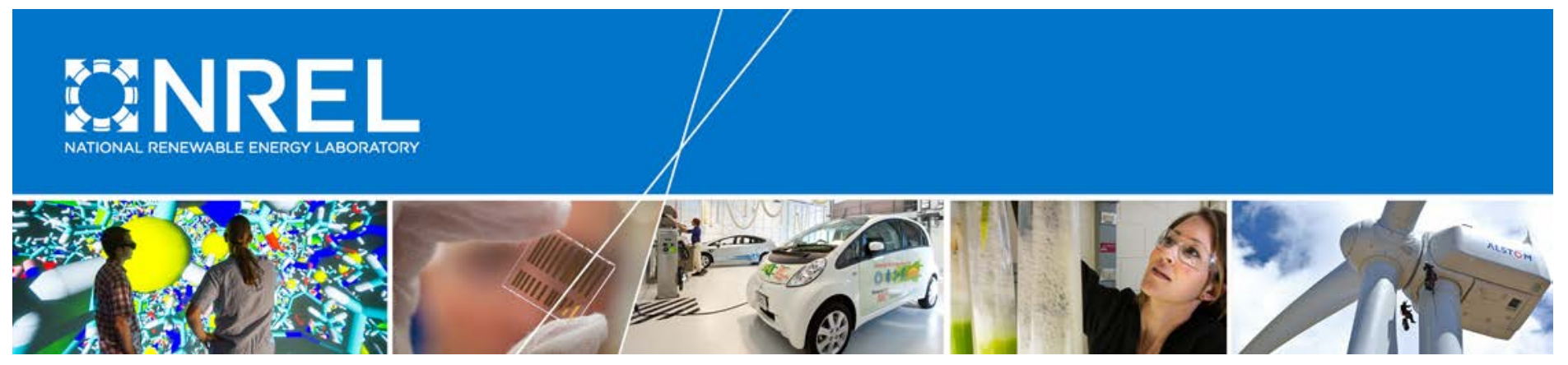

\title{
Degradation in PV Encapsulant Strength of Attachment: An Interlaboratory Study Towards a Climate-Specific Test
}

\section{Preprint}

David C. Miller, Eleonora Annigoni, Amal Ballion, Jayesh G. Bokria, Laura S. Bruckman, David M. Burns, Xinxin Chen, Jiangtao Feng, Roger H. French, Sean Fowler, Christian C. Honeker, Michael D. Kempe, Hussam Khonkar, Michael Köhl, Laure-Emmanuelle Perret-Aebi, Nancy H. Phillips, Kurt P. Scott, Fanny Sculati-Meillaud, and John $\mathrm{H}$. Wohlgemuth

Presented at the 43rd IEEE Photovoltaic Specialists Conference Portland, Oregon June 5-10, 2016

(c) 2016 IEEE. Personal use of this material is permitted. Permission from IEEE must be obtained for all other uses, in any current or future media, including reprinting/republishing this material for advertising or promotional purposes, creating new collective works, for resale or redistribution to servers or lists, or reuse of any copyrighted component of this work in other works.

NREL is a national laboratory of the U.S. Department of Energy Office of Energy Efficiency \& Renewable Energy Operated by the Alliance for Sustainable Energy, LLC

This report is available at no cost from the National Renewable Energy Laboratory (NREL) at www.nrel.gov/publications.

Conference Paper

NREL/CP-5J00-65539

July 2016 


\section{NOTICE}

The submitted manuscript has been offered by an employee of the Alliance for Sustainable Energy, LLC (Alliance), a contractor of the US Government under Contract No. DE-AC36-08GO28308. Accordingly, the US Government and Alliance retain a nonexclusive royalty-free license to publish or reproduce the published form of this contribution, or allow others to do so, for US Government purposes.

This report was prepared as an account of work sponsored by an agency of the United States government. Neither the United States government nor any agency thereof, nor any of their employees, makes any warranty, express or implied, or assumes any legal liability or responsibility for the accuracy, completeness, or usefulness of any information, apparatus, product, or process disclosed, or represents that its use would not infringe privately owned rights. Reference herein to any specific commercial product, process, or service by trade name, trademark, manufacturer, or otherwise does not necessarily constitute or imply its endorsement, recommendation, or favoring by the United States government or any agency thereof. The views and opinions of authors expressed herein do not necessarily state or reflect those of the United States government or any agency thereof.

This report is available at no cost from the National Renewable Energy Laboratory (NREL) at www.nrel.gov/publications.

Available electronically at SciTech Connect http:/www.osti.gov/scitech

Available for a processing fee to U.S. Department of Energy and its contractors, in paper, from:

U.S. Department of Energy

Office of Scientific and Technical Information

P.O. Box 62

Oak Ridge, TN 37831-0062

OSTI http://www.osti.gov

Phone: 865.576.8401

Fax: 865.576.5728

Email: reports@osti.gov

Available for sale to the public, in paper, from:

U.S. Department of Commerce

National Technical Information Service

5301 Shawnee Road

Alexandria, VA 22312

NTIS http://www.ntis.gov

Phone: 800.553 .6847 or 703.605 .6000

Fax: 703.605.6900

Email: orders@ntis.gov 


\title{
Degradation in PV Encapsulant Strength of Attachment: An Interlaboratory Study Towards a Climate-Specific Test
}

\author{
David C. Miller ${ }^{1}$, Eleonora Annigoni ${ }^{2}$, Amal Ballion ${ }^{3}$, Jayesh G. Bokria ${ }^{4}$, Laura S. Bruckman ${ }^{5}$, David M. Burns ${ }^{6}$, \\ Xinxin Chen ${ }^{7}$, Jiangtao Feng ${ }^{7}$, Roger H. French ${ }^{5}$, Sean Fowler ${ }^{8}$, Christian C. Honeker ${ }^{9}$, \\ Michael D. Kempe ${ }^{1}$, Hussam Khonkar ${ }^{10}$, Michael Köhl ${ }^{3}$, Laure-Emmanuelle Perret-Aebi ${ }^{11}$, Nancy H. Phillips ${ }^{6}$, \\ Kurt P. Scott ${ }^{12}$, Fanny Sculati-Meillaud ${ }^{2}$, and John H. Wohlgemuth ${ }^{1}$
}

\author{
${ }^{1}$ National Renewable Energy Laboratory (NREL), 15013 Denver West Parkway, Golden, CO 80401, USA \\ ${ }^{2}$ École Polytechnique Fédérale de Lausanne (EPFL), Rue de la Maladière 71B, Ch-2002 Neuchâtel, Switzerland \\ ${ }^{3}$ Fraunhofer Institute for Solar Energy Systems (ISE), Heidenhofstrasse 2, 79110 Freiburg, Germany \\ ${ }^{4}$ Specialized Technology Resources, Inc. (STR), 10 Water Street, Enfield, CT 06082, USA \\ ${ }^{5}$ Case Western Reserve University (CWRU), White 538, 10900 Euclid Avenue, Cleveland, OH 44106, USA \\ ${ }^{6}$ The 3M Company, 3M Center, Building 235-67-15, St. Paul, MN 55144, USA \\ ${ }^{7}$ China National Electric Apparatus Research Institute Co., Ltd. (CEI), Guangzhou, 510663, P. R. China \\ ${ }^{8}$ Q-Lab Corporation, 800 Canterbury Road, Cleveland, OH, 44145, USA \\ ${ }^{9}$ Fraunhofer Center for Sustainable Energy Systems (CSE), 5 Channel Center, Boston, MA 02210, USA \\ ${ }^{10}$ King Abdulaziz City for Science and Technology (KACST), 17 King Abdullah Road, Riyadh, 11442, Saudi Arabia \\ ${ }^{11}$ Centre Suisse d'Electronique et Microtechnique SA. (CSEM), Rue Jaquet-Droz 1, Ch-2002 Neuchâtel, Switzerland \\ ${ }^{12}$ Atlas Material Testing Technology L.L.C., 1500 Bishop Court, Mount Prospect, IL 60056, USA
}

\begin{abstract}
Reduced strength of attachment of the encapsulant resulting from the outdoor environment, including ultraviolet (UV) radiation, may decrease photovoltaic (PV) module lifetime by enabling widespread corrosion of internal components. To date, few studies exist showing how the adhesion of PV components varies with environmental stress. We have conducted an interlaboratory experiment to provide an understanding that will be used to develop climatic specific module tests. Factors examined in the study included the UV light source (lamp type), temperature, and humidity to be proposed for use in accelerated aging tests. A poly (ethylene-co-vinyl acetate) (EVA) formulation often used in veteran PV installations was studied using a compressive shear test - to quantify the strength of attachment at the EVA/glass interface. Replicate laminated glass/polymer/glass coupon specimens were weathered at 12 institutions using a variety of indoor chambers or field aging. Shear strength, shear strain, and toughness were measured using a mechanical loadframe for the compressive shear test, with subsequent optical imaging and electron microscopy of the separated surfaces.
\end{abstract}

Index Terms - durability, reliability, Xenon

\section{INTRODUCTION}

The adhesion of encapsulation was identified as a critical issue in the early development of photovoltaic (PV) module technology [1],[2]. That work sought to develop encapsulation formulations whose cohesive strength exceeded the adhesive strength at interfaces. To achieve this, a bifunctional coupling agent (with chemical groups on one end being reactive with glass and chemical groups on the opposite end being reactive with the encapsulant) was developed that could be included in the formulation to act as a primer. It was theorized at the time that the coupling agent would form an interpenetrating network, i.e., an intermediate layer covalently bonded to the glass and encapsulant [1]. Since then, delamination has often been observed in veteran PV installations in a wide variety of locations and climates [3]. Systematic quantitative studies of encapsulant adhesion are, however, presently lacking in the PV literature. In their absence, qualitative examinations provide anecdotal support for insights including that the encapsulation/cell interface is typically weaker than the encapsulation/glass interface [3],[4],[5], with observations of delamination being reported at both interfaces in veteran installations [3]; that the use of primer, enabled with an adequate degree of cure, facilitates good adhesion [1],[2],[6]; and that delamination often precedes corrosion in fielded PV modules [1],[7]. The widespread observation of delamination [3] suggests that it may be aided by the complex history of conditions present during the life of a module. It remains to be established if encapsulant adhesion correlates with discoloration.

Existing protocols examining the general robustness of PV modules include the IEC 61730 (safety) [8] and IEC 61215 (type qualification) [9] standards. Specifically, IEC 61730-2 edition 2 only directly examines adhesion of the backsheet (using a Peel test) or cemented joint (using an Overlap Shear test) whereas IEC 61215-2 only directly examines adhesion of cables and the junction-box (Robustness of Terminations tests), indirectly examining adhesion of the encapsulant following the ultraviolet (UV) Preconditioning, Humidity Freeze, and Thermal Cycling tests. IEC 61215-2, however, does specify an ultraviolet radiation (UV) preconditioning of $54 \mathrm{MJ} \cdot \mathrm{m}^{-2}\left(15 \mathrm{kWh} \cdot \mathrm{m}^{-2}\right)$, which would be encountered after 40 days of field exposure to the AM1.5G UV spectrum. IEC 61730-2 now prescribes up to $4 \mathrm{x}$ this UV exposure - also much less than a 25 year service life. The recent development of standards related to the materials and components used in PV modules, e.g., the IEC 62788 series, has highlighted the need for improved understanding of adhesion in PV technology that might also apply to encapsulation.

We have conducted an interlaboratory study to provide the understanding that will be used to develop climate-specific sequence tests, e.g., the IEC 62892 series. The experiments 
and results for the examination of the degradation of strength of attachment will be described here.

The goals of the encapsulant attachment study include:

-Quantify the significance of the factors of UV, temperature $(T)$, relative humidity $(R H)$, and time. Which factors most reduce the attachment during weathering? What range of values should be applied for aging?

-Determine if there is significant coupling between $U V, T$, and $R H$. What factors should be applied in a weathering test for attachment?

-Investigate the spectral requirements for light sources, e.g., compare Xe-arc or UVA-340 fluorescent lamps. Does visible light affect aging?

\section{EXPERIMENTAL}

Glass/encapsulant/glass coupons were artificially aged using a variety of different steady state conditions. The glass consisted of textured Solite glass (AGC Solar/Asahi Glass Co.), representative of glass used in the PV industry. Unlike the silica glass used in Ref. [10], Solite does absorb some terrestrial UV. Furthermore, Solite is subject to solarizationits UV cut-off wavelength (where it becomes $10 \%$ transmitting) was verified here to change from $295 \mathrm{~nm}$ to 297 $\mathrm{nm}$ following UV exposure. A single encapsulation material, "EVA-B" as in Ref. [10]-similar to the STR product PHOTOCAP 15295P/UF - was studied in the attachment test. EVA-B represents the material found in many recently examined veteran installations [3].

Weathering specimens were made by first laminating a 36.8$\mathrm{cm} \times 36.8-\mathrm{cm}$ glass/encapsulant/glass stack using a periphery inset lamination frame composed of a matched-thickness removable layer to ensure good $(0.45 \pm 0.03 \mathrm{~mm})$ thickness uniformity. Lamination was carried out for 8 minutes at $145^{\circ} \mathrm{C}$. The resulting samples were then diced into 76- $\mathrm{mm} \times 76-\mathrm{mm}$ coupons using an abrasive water jet saw (Precision Waterjet Co.) Water jet cutting was found to provide a surface roughness comparable to carbide or diamond resin dicing blades (average and root-mean-square roughness on the order of 1-2 $\mu \mathrm{m})$, but importantly with less chipping of the exposed glass surfaces at the specimen edges. Diced coupons were then preconditioned in temperature/humidity chambers for at least 1 month to achieve a baseline moisture concentration in the polymer similar to that applied in the different artificial aging tests.

The description here is primarily focused on materials exposed using Ci5000 chambers (ATLAS Material Testing Technology LLC), which are equipped with a Xe lamp and "Right Light" filter. The default exposure settings for the Ci5000 used an irradiance of $1.0 \mathrm{~W} \cdot \mathrm{m}^{-2} \cdot \mathrm{nm}^{-1}$ at $340 \mathrm{~nm}$; an indoor chamber temperature set point of $60^{\circ} \mathrm{C}$; an uncontrolled black panel temperature; and a chamber atmosphere controlled to $30 \% R H$, resulting in a measured sample temperature of $\sim 63^{\circ} \mathrm{C}$. Exposure times are reported for the cumulative radiant exposure, $H$, provided for the wavelength range $295 \leq \lambda \leq 360$ $\mathrm{nm}$ so that the results may be more readily compared between Xe and UVA-340 sources [11].
The attachment coupons were aged for $0,15,30,45,90$, 135 , or 180 cumulative days. Strength measurements were obtained after the coupons were diced into 25-mm x 25-mm specimens using the water jet cutter and then conditioned for at least 2 weeks to equilibrate their internal moisture content similar to that during aging. The coupons were marked before dicing to be able to distinguish the specimens' interior and periphery. Two coupons were aged to each cumulative UV dose. At least 5 replicates are used for the periphery measurements, where the orientation of the periphery specimens was alternated (i.e., the outside edge was in-line or perpendicular to the applied displacement).

One additional experiment was performed to quantify the effect of specimen conditioning. Here, unaged specimens were either desiccated or maintained at $45^{\circ} \mathrm{C}$ and $85 \% \mathrm{RH}$ for 1 month before testing in addition to specimens subject to $\mathrm{H}=333 \mathrm{GJ} \cdot \mathrm{m}^{-2}$ at $60^{\circ} \mathrm{C} / 50 \% \mathrm{RH}$ that were dessicated for 1 month after aging.

As shown in Fig. 1, attachment was measured using the compressive shear test (CST) method with custom grips, similar to Ref. [6]. The displacement controlled CST was performed at a constant strain rate of $0.05 \mathrm{~s}^{-1}$ (for $\dot{\gamma}_{x y}=\dot{\delta} \cdot h_{i}{ }^{-1}$, where $\dot{\gamma}_{x y}$ represents the strain rate, $\mathrm{s}^{-1} ; \dot{\delta}$ the displacement rate, $\mathrm{m} \cdot \mathrm{s}^{-1}$; and $h_{\mathrm{i}}$ the initial encapsulation specimen thickness of $0.45-\mathrm{mm}$ ) and data acquisition rate of $100 \mathrm{~Hz}$ using a mechanical load-frame (ReNew 1125/75/82, Instru-Met Corp.), load-cell (GR A30-33, Instron), and the custom grips. Two universal joints (Grey and Prior Machine Co.) were used to compensate the alignment of the grips during the test, shown in Fig. 1 (inset). Data were excluded for samples with substrate cracking prior to failure. Substrate cracking, typically visually or auditorily evident during testing, often corresponded to excursions in the data profiles. Good dicing and specimen handling practices to maintain good surface quality and prevent chips or cracks at the edges of the glass were critical to preventing substrate cracking.

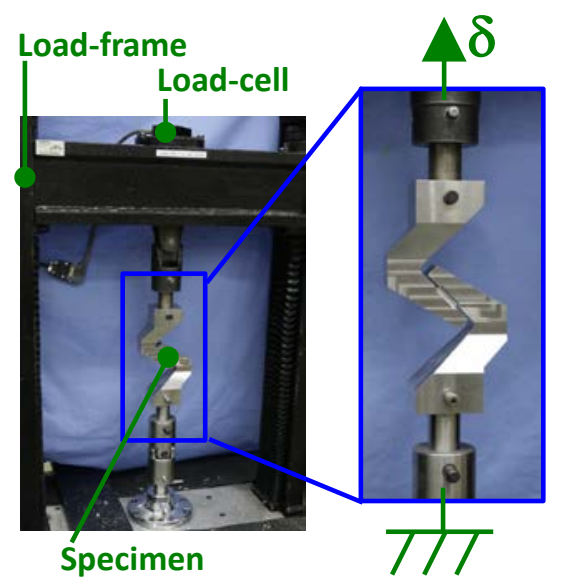

Fig. 1. The equipment for the compressive shear test includes a load-frame, load-cell, and custom grips. As indicated in the inset, specimens are sheared apart when the movable top grip is displaced relative to the fixed lower grip. 
As indicated in Equation 1, the strain $\left(\gamma_{x y}\right)$ was calculated from the crosshead displacement $(\delta, \mathrm{m})$ based on the initial $h_{\mathrm{i}}$ and known test angle, $\theta$, of $45^{\circ}$. Because the strain was inferred from the crosshead displacement, it does not account for the compliance of the instrument and grips. As in Equation 2 , shear stress was calculated from the measured load $(F, \mathrm{~N})$ based on the initial specimen geometry (the area, $A, \mathrm{~m}^{2}$ ) and $\theta$. Toughness was automatically calculated from the measured area of stress/strain data profile.

$$
\begin{aligned}
& \gamma_{x y}=\delta \cos [\theta] \cdot h_{i}^{-1}=\frac{\sqrt{2} \delta}{2 h_{i}} \\
& \tau_{x y}=F \cos [\theta] \cdot A^{-1}=\frac{\sqrt{2} F}{2 A}
\end{aligned}
$$

\section{RESULTS}

Fig. 2 shows the results for Xe aged specimens including the maximum shear strength $\left(\max \left[\tau_{\mathrm{xy}}\right], \mathrm{Pa}\right)$ and toughness $\left(U_{T}\right.$, $\left.\mathrm{J} \cdot \mathrm{m}^{-3}\right)$. The $\max \left[\tau_{\mathrm{xy}}\right]$ was taken from the peak of the stress/strain data profile; $U_{\mathrm{T}}$ was determined from the start of the test, $\gamma_{x y}=0$, up to failure, the maximum $\gamma_{x y}$. Results are shown for specimens cut from the interior (-i) and periphery (p) of the coupons. The equivalent IEC 61215-2 UV dose $(295 \leq \lambda \leq 360 \mathrm{~nm})$ is indicated in the bottom left of the figure for Xe (left hash mark) and UVA-340 sources (right hash mark). Fig. 2 shows a significant loss of strength, exceeding $50 \%$ of the original strength. A similar decrease in attachment strength exceeding $66 \%$ of the original strength was observed for specimens aged at Fraunhofer ISE using fluorescent UV lamps, not shown. In that case, asymptotic loss similar to that depicted in Fig. 2 was also observed for specimens aged in that chamber (operated at $2.2 \mathrm{~W} \cdot \mathrm{m}^{-2} \cdot \mathrm{nm}^{-1}$ at $340 \mathrm{~nm}$, with the chamber temperature set point of $60^{\circ} \mathrm{C}$, and its atmosphere controlled to $50 \% R H$ ).

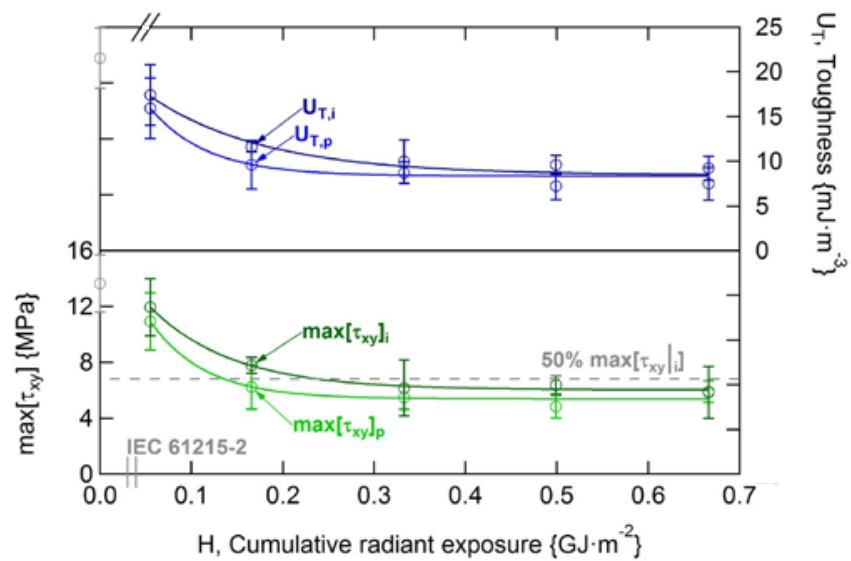

Fig. 2. Change in $\max \left[\tau_{\mathrm{xy}}\right]$ and $U_{\mathrm{T}}$ with $H(295 \leq \lambda \leq 360 \mathrm{~nm})$ for coupons aged in the NREL Ci5000 chamber (Xe lamps, with the chamber controlled at $60^{\circ} \mathrm{C}$ and $50 \% R H$ ).

Fig. 3 shows representative (median) $\tau_{\mathrm{xy}} / \gamma_{\mathrm{xy}}$ profiles from the data in Fig. 2. The elastic region (initial $\tau$ and $\gamma$ ) of the specimens is not overtly affected with age. The hyperelastic behavior (e.g., observed at the greatest $\tau$ and $\gamma$ for the unaged specimen, which may strain nearly 500\% - five times the encapsulant thickness) no longer occurs with prolonged aging (e.g., where strain is limited to $300 \%$ for $H \geq 0.17 \mathrm{MJ} \cdot \mathrm{m}^{-2}$ ). The self-similar shape of the data profiles in Fig. 3 is consistent with the general correlation between $\tau_{\mathrm{xy}}$ and $U_{\mathrm{T}}$ in Fig. 2. Some variability in sharpness of the $\tau_{x y}$ peak was observed in specimens at all ages.

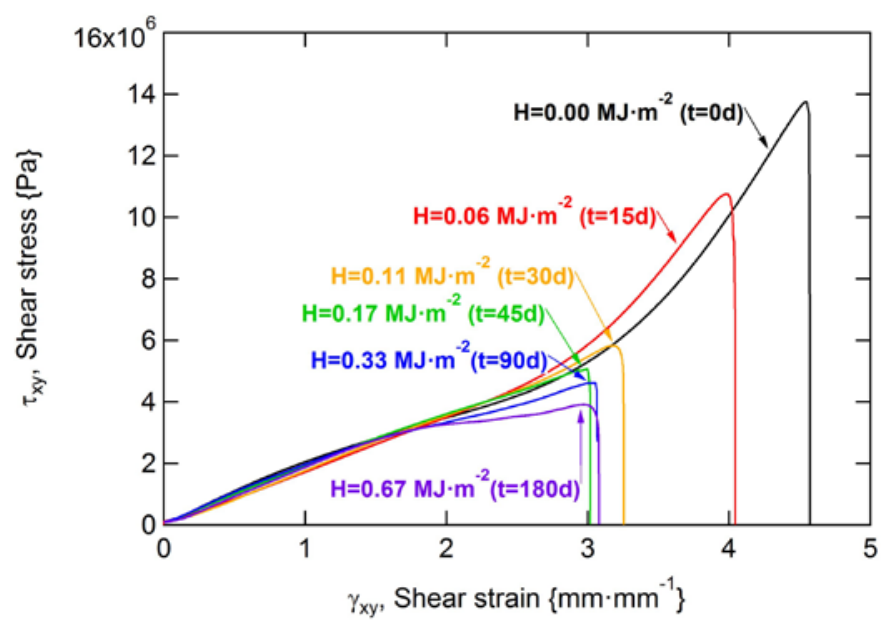

Fig. 3. Overlay of $\tau_{x y} / \gamma_{x y}$ profiles for the median of the data profiles (from periphery specimens) in Fig. $1 . H$ is noted along with the cumulative test duration (days).

Table provides the previous $\max \left[\tau_{\mathrm{xy}}\right]$ data in Fig. 2 for $H$ $=0 \mathrm{MJ} \cdot \mathrm{m}^{-2}$ with additional results from the sets of pre- or postconditioned specimens (any aged specimens periphery located). Additional specimens in Table include: (a) unaged specimens desiccated at $25^{\circ} \mathrm{C}$; (b) unaged specimens maintained at $45^{\circ} \mathrm{C}$ and $85 \% R H$; and (c) specimens aged for $H$ $=333 \mathrm{MJ} \cdot \mathrm{m}^{-2}$ and then desiccated at $25^{\circ} \mathrm{C}$ for 1 month.

TABLE I

COMPARISON OF CONDITIONED SPECIMENS RELATIVE TO FIG. 2.

\begin{tabular}{|c|c|c|c|}
\hline $\begin{array}{c}H, \text { RADIANT } \\
\text { EXPOSURE } \\
\left\{\mathrm{GJ} \cdot \mathrm{m}^{-2}\right\}\end{array}$ & PRE-CONDITION & $\begin{array}{c}\max \left[\mathrm{t}_{\mathrm{xy}}\right] \\
\{\mathrm{MPa}\}\end{array}$ & $\begin{array}{c}U_{\mathrm{T}}, \\
\text { TOUGHNESS } \\
\{\mathrm{mJ}\}\end{array}$ \\
\hline \hline 0.000 & Fig. 2, desiccated & $13.64 \pm 2.04$ & $21.540 \pm 3.388$ \\
\hline 0.000 & (a), desiccated & $14.45 \pm 1.31$ & $23.720 \pm 2.995$ \\
\hline 0.000 & (b), $45^{\circ} \mathrm{C} / 85 \% R H$ & $9.71 \pm 1.08$ & $14.640 \pm 1.988$ \\
\hline 0.333 & Fig. $2,45^{\circ} \mathrm{C} / 85 \% R H$ & $4.84 \pm 0.75$ & $7.206 \pm 1.321$ \\
\hline 0.333 & (c), desiccated & $7.95 \pm 0.98$ & $12.100 \pm 1.889$ \\
\hline
\end{tabular}

Fig. 4 shows the previous $\max \left[\tau_{\mathrm{xy}}\right]$ data in Fig. 2, overlaid with additional results from specimens weathered at $3 \mathrm{M}$ at $30 \% \mathrm{RH}$. All specimens in Fig. 4 were aged at the same irradiance (1.0 $\mathrm{W} \cdot \mathrm{m}^{-2} \cdot \mathrm{nm}^{-1}$ at $\left.340 \mathrm{~nm}\right)$ and chamber temperature $\left(60^{\circ} \mathrm{C}\right.$, resulting in a measured specimen temperature of $\left.\sim 63^{\circ} \mathrm{C}\right)$, but at different moisture concentrations $(30 \% R H$ or $50 \% R H)$. As in Fig. 2, and Fig. 4, the periphery-located specimens are more rapidly affected than those obtained from the interior of the aged coupons. This may be quickly verified in each figure as the lighter of the like-colored data (the periphery-located specimens) are more affected (greater reduction in $\max \left[\tau_{\mathrm{xy}}\right]$ ) 
than the accompanying darker like-colored data. As in the other results, a fit has been added to the discrete data points strictly to guide the eye. For example, $\max \left[\tau_{\mathrm{xy}}\right]$ is decreased through the experiment at $50 \% R H$, resembling asymptotic behavior, represented using an exponential decay fit. $\max \left[\tau_{\mathrm{xy}}\right]$ appears to be enhanced for $H<166 \mathrm{MJ} \cdot \mathrm{m}^{-2}$ at $30 \% R H$; therefore, a more complex sigmoidal fit has been applied to group the data.

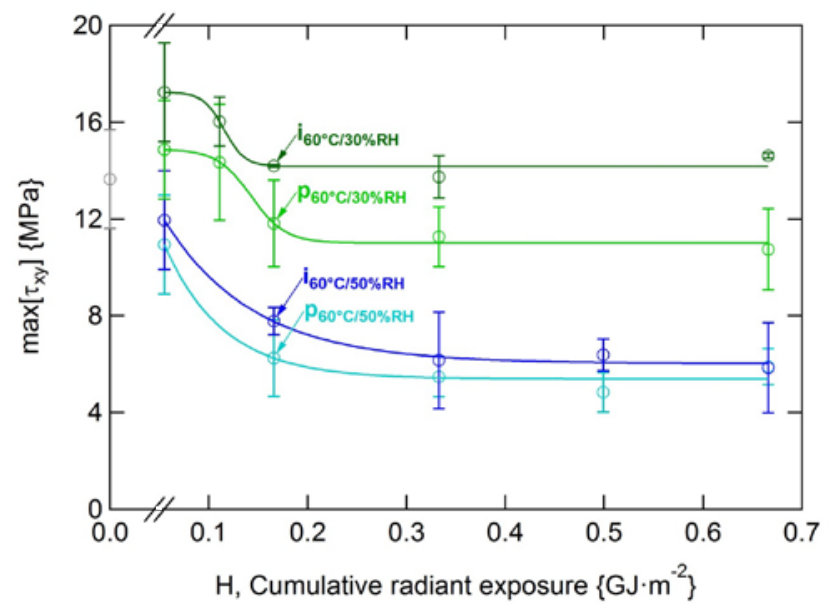

Fig. 4. Overlay of data for samples weathered in separate Xe chambers at the same irradiance $\left(1.0 \mathrm{~W} \cdot \mathrm{m}^{-2} \cdot \mathrm{nm}^{-1}\right.$ at $\left.340 \mathrm{~nm}\right)$ and chamber temperature $\left(60^{\circ} \mathrm{C}\right)$ but $R H$ of: (a) $30 \%$, colored green; and (b) $50 \%$, colored blue.

Change in $\tau_{x y}$ with age is examined in Fig. 5 for specimens weathered using separate $\mathrm{Xe}$ chambers at $3 \mathrm{M}$ maintained at different temperature, but all using $1.0 \quad \mathrm{~W} \cdot \mathrm{m}^{-}$ ${ }^{2} \cdot \mathrm{nm}^{-1}$ at $340 \mathrm{~nm}$ and a $30 \%$ chamber $R H$. Limited (if any) change is observed for the specimens aged at $45^{\circ} \mathrm{C}$; a possible increase in attachment strength is initially observed for $60^{\circ} \mathrm{C}$; and an asymptotic decrease in $\tau_{\mathrm{xy}}$ is observed for $80^{\circ} \mathrm{C}$. As in Fig. 5, a lesser decrease in $\tau_{x y}$ was seen for specimens aged at Fraunhofer ISE using a fluorescent UV chamber maintained at $40^{\circ} \mathrm{C}$ (not shown). The asymptotic decrease in $\tau_{\mathrm{xy}}$ for the moisture equilibrated specimens aged at $80^{\circ} \mathrm{C} / 30 \% \mathrm{RH}$ in Fig. 5 is less $\left(\Delta \max \left[\tau_{\mathrm{xy}}\right]\right.$ of $41 \%$ from the dry reference) than that observed in Fig. 2 for $60^{\circ} \mathrm{C} / 50 \%$ RH $\left(\Delta \max \left[\tau_{x y}\right]\right.$ of $\left.54 \%\right)$. As in Fig. 5, a substantial asymptotic decrease in $\tau_{\mathrm{xy}}(12.3 \mathrm{MPa})$ was seen for a specimen aged at Fraunhofer ISE using a fluorescent UV chamber maintained at $80^{\circ} \mathrm{C}$ (not shown).

The typical morphology of failed specimens is shown in Fig. 6. For many of the specimens, the majority of the encapsulant typically remained on one side of the detached glass. This was confirmed using scanning electron microscopy (not shown) and may be observed at a site along the bottom edge of the detached specimen substrate, identified with an arrow in the inset of Fig. 6. To clarify, a thin layer of encapsulant typically remained adjacent to the textured surface of the superstrate. Most often, the majority of the encapsulant remained on the substrate, suggesting UV damage near the incident polymer/glass interface. This was corroborated during specimen preparation for failure analysis, when the irradiated surface was much easier to separate when dicing transmittance specimens [10] into smaller pieces for analysis. Furthermore, the detached surface was used to identify specimens facing differently during weathering at one laboratory (with the serial number surface scribed towards the lamp), when the opposite specimen orientation was used at the other laboratories.

Localized delamination was sometimes observed at specimen edges. An example appears in Fig. 6, where a crescent shaped portion of encapsulant is detached at the left edge of specimen substrate. Delamination at the specimen edges always occurred along the loading direction, regardless of specimen orientation.

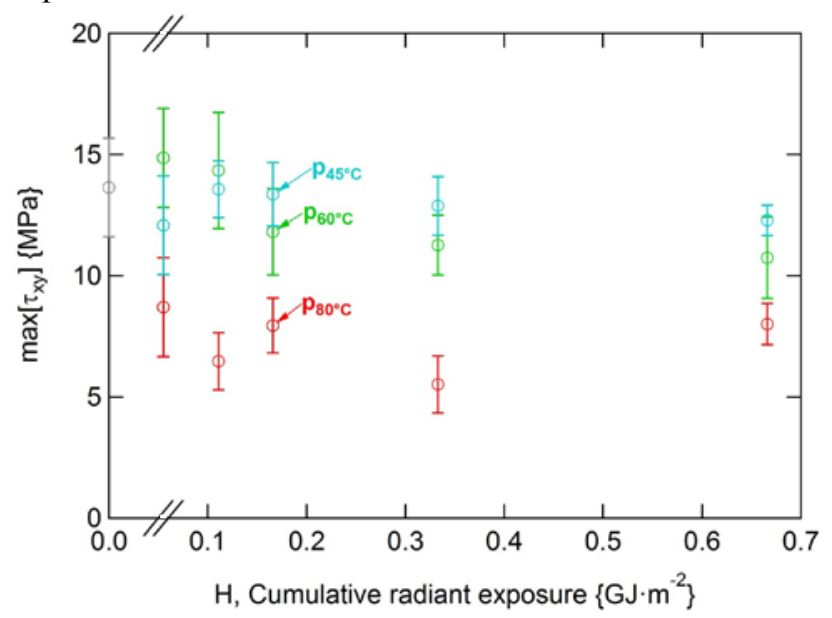

Fig. 5. Comparison of change in $\tau_{\mathrm{xy}}$ with applied temperature. The same default irradiance and $R H$ conditions were used in separate Xe chambers, maintained at $45^{\circ} \mathrm{C}, 60^{\circ} \mathrm{C}$, or $80^{\circ} \mathrm{C}$, respectively.

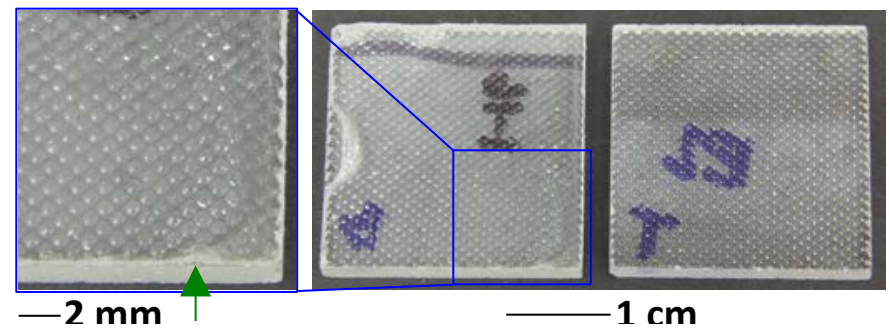

Fig. 6. Optical photograph showing the typical morphology of failed specimens. An arrow marks an area on the inset where the remaining encapsulation may be discerned from the glass substrate.

\section{DISCUSSION}

Regarding the results in Fig. 2, the asymptotic behavior suggests an overriding degradation mode such as UV- or hydrothermal- degradation. The data further suggest an asymptotic limit for the degradation of the $\max \left[\tau_{\mathrm{xy}}\right]$ at the EVA/glass interface. From Ref. [12], the final $H$ is equivalent to 4.5 years in Phoenix, AZ (based solely on the UV dose between $295 \mathrm{~nm}$ and $385 \mathrm{~nm}$ ). The decrease in strength in Fig. 2 exceeds $25 \%$, the threshold typically used in the relative thermal index (RTI, i.e., UL 746C) test and 50\%, the threshold in the relative thermal endurance (RTE i.e., IEC 60216) test, which is also applied for cemented joints in IEC 61730-2. The loss of strength therefore raises the question: should the traditional test protocol (e.g., 50\% loss of strength) or the device application (such as a minimum threshold) motivate 
decision making about the attachment of weathered encapsulant interfaces?

The loss of the hyperelastic in Fig. 3 suggests the results in Fig. 2 are dominated by the mechanical properties of the EVA. An increase in crosslink density in the EVA might explain the embrittlement in Fig. 3; such behavior has been observed in the gel content measurements of artificially aged EVA [13]. Regarding the rounding of the $\tau_{x y}$ peaks in Fig. 3, this likely relates to the suddenness of failure, where rounding often suggests yielding or slip at the interface.

The additional desiccated unaged specimens, marked as (a) in Table, resemble the previous unaged specimens. This overlap demonstrates that the test is repeatable. The data importantly clarify the meaning of the unaged specimens in Fig. 2, Table, Fig. 4, and Fig. 5, which were obtained for desiccated specimens to standardize the presentation of results between different experiments. The remaining data in Fig. 2, Fig. 4, and Fig. 5 (not colored gray), however, were obtained from aged specimens controlled at the internal water concentration present during UV weathering.

The wet pre-conditioned unaged specimens, marked (b) in Table, show a $3.93 \mathrm{MPa}$ reduction in $\max \left[\tau_{\mathrm{xy}}\right]$ relative to the desiccated reference specimens in Fig. 2. The effect of added moisture is comparable to the effect of continued chamber weathering, i.e., an additional $4.87 \mathrm{MPa}$ reduction in $\max \left[\tau_{\mathrm{xy}}\right]$. This is confirmed in the reverse characterization, where the $\max \left[\tau_{\mathrm{xy}}\right]$ for aged specimens, (c) in Table, increased by 3.11 $\mathrm{MPa}$ when water was removed. Table importantly confirms that controlling the moisture content of specimens at the time of each measurement is essential to measurement and interpretation of weathering studies related to attachment.

The significant difference in results at $30 \% \mathrm{RH}$ and $50 \%$ $R H$ confirms that moisture plays a significant role in change in attachment between EVA and glass. This suggests the mode of hydrothermal degradation in Fig. 4. The more rapid and significant reduction in $\max \left[\tau_{\mathrm{xy}}\right]$ at the coupon periphery may result from oxygen facilitated degradation. For example, oxygen bleaching was observed to affect the degradation and subsequent properties of transmittance specimens in Ref. [13]. To clarify, the location-specific results should not follow from the equilibration of moisture, as the aged specimens were preconditioned before weathering as well as after aging and also after being diced. An initial increase in strength of attachment with aging, as suggested for the specimens aged at $30 \% \mathrm{RH}$, can occur, e.g., based on increased substrate bond population.

An acute dependence on the temperature present during weathering is evident from the very different data profiles in Fig. 5. The disparate profiles may result from: (1) a threshold of $U V, T$, or $R H$ required to cause substantial damage; (2) the consequences of absorbed moisture, i.e., water facilitated polymer plasticization or hydrothermal degradation instead of $U V$ degradation; or (3) phase transition, where EVA melts at $\sim 60^{\circ} \mathrm{C}$. Additional experiments in progress, including examination at $40^{\circ} \mathrm{C}, 60^{\circ} \mathrm{C}$, and $80^{\circ} \mathrm{C}$ but with no light present as well as characterization at multiple temperatures above the melting transition for EVA should clarify the meaning of Fig.
5. The results in Fig. 5 may fortuitously suggest that in many areas of the world, where extreme $T$ and $R H$ are not both present, there may be little or no loss of attachment with UV exposure. In comparison, Weathering at $85^{\circ} \mathrm{C}$ and $20 \% R H$ is presently advocated in the proposed IEC $62788-7-2$ weathering of PV polymeric materials standard.

The failure morphology in Fig. 6 may identify cohesive failure near the irradiated interface rather than delamination. This observation is consistent with the loss of hyperelastic behavior with age in Fig. 3. If so, the $\max \left[\tau_{\mathrm{xy}}\right]$ and $U_{T}$ in Fig. 2 are limited by EVA degradation, not the interface with the glass. Failure may instead occur at the interface between an interpenetrating network between the EVA and primer, where the network has a more significant thickness than immediately evident in Ref. [1]. It remains to be validated if either failure mode is observed in PV modules.

Regarding the specimen appearance in Fig. 6, the EVA was usually not overtly discolored except at higher temperatures $\left(80^{\circ} \mathrm{C}\right)$. The reduced UV transmittance (i.e., UV cut-off wavelength of $295 \mathrm{~nm}$ ) of the Solite glass superstrate used in this study likely reduces UV damage, thereby contributing to the observed neutral appearance.

The localized delamination at the edges in Fig. 6 may result from increased stress intensity, which was observed in finite element analysis of the test method [6]. The rounding of the $\tau_{\mathrm{xy}}$ peaks in Fig. 3 may result from such inelastic deformation at the edges of the encapsulant.

Several considerations might provide further understanding regarding the degradation observed in this study. First, the textured glass may affect the results by creating a heterogeneous stress field near the EVA/glass interface, moving the failure zone away from the interface. Textured glass is commonly used in PV modules. Second, the mechanical state invoked during the CST (which here created a stress by applying a large displacement) can vary significantly from that in a fielded PV module (which can include stresses concentrated about components including cells and interconnect ribbons as well as about voids/flaws in the encapsulant itself). The study here would also benefit from a fracture mechanics test method, which would directly examine adhesion rather than strength of attachment. Fracture mechanics can be directly related to the underlying physics of adhesion in order to also study its degradation. Third, it is unclear if the best suited aging method is applied in this study. While some weakness is identified here based on failure proximate to the irradiated interface, the coupling agents developed for EVA were theorized to be robust to UV [1],[2]. Those early studies instead aged using immersion in heated or boiling water. $T$ and/or $R H$ cycling might instead more closely emulate the degradation seen in PV modules. A more recent study [14] instead examines if UV weathering could be applied prior to the Cyclic ("Dynamic") Mechanical Load test, followed by the Humidity Freeze test followed by the Damp Heat test to invoke delamination and subsequent corrosion damage in PV modules. The steady state weathering results presented here will be compared to those obtained from identical coupons, naturally aged at locations including Miami 
and Phoenix. Fourth, metal corrosion (e.g., of grid lines or interconnects, possibly facilitated by acetic acid) or glass corrosion (e.g., ion migration following with potential induced degradation) or gas formation (from residual reactions) may not occur in the simple coupon material-only specimens examined here. Fifth, manufacturing and process control (glass cleaning and contamination control) may significantly contribute to loss of adhesion in veteran PV modules. In this case, components in addition to those used in the specimens in this study would also be required for examination. Manufacturing-related adhesion problems might be better addressed in the IEC 62941 standard for a quality management system in PV manufacturing rather than IEC 61730 or IEC 62125. Lastly, it should be pointed out that only permanent UV damage has been examined here whereas UV present during an applied mechanical stress may have different effects and consequences. Remember also that the glass/encapsulant interface may not be weakest interface in many PV modules.

\section{CONCLUSIONS}

The UV photodegradation of the strength of attachment of PV encapsulation materials is under examination. Key interim results of the interlaboratory study include the following:

Evidence of permanent damage from UV weathering was identified and attributed to the degradation of the EVA encapsulant. The strongest evidence comes from the many specimens showing failure proximate to their UV irradiated surface. Asymptotic degradation occurred during a UV dose of $<700 \mathrm{MJ} \cdot \mathrm{m}^{-2}$, suggesting a 6 -month artificial aging test may be appropriate for UV weathering. It is cautioned that combined UV and mechanical stress, not examined here, may have different effects and consequences.

The results of weathering have been found to be very condition-sensitive, i.e., likely very factor coupled. For example, the loss of strength for weathering at $80^{\circ} \mathrm{C}$ was found to be much greater than that obtained at $60^{\circ} \mathrm{C}$. Regarding moisture, plasticization and hydrothermal degradation may contribute to the loss of strength. So, in areas of the world where extreme $T$ and $R H$ are not both present, there may be little or no loss of attachment with UV exposure. The results here suggest careful consideration of temperature and humidity in weathering or qualification related standards.

Cohesive failure of the EVA or delamination between EVA and a thick interpenetrating network with the coupling agent (primer) is implied from the failure morphology observed in this study. This result may follow from: the use of textured glass (and corresponding heterogeneous stress field near the interface); the mechanical state invoked during the CST (where stress results from a large applied displacement); the steady state nature of the weathering applied (as opposed to a more complex or cyclic aging); and the underlying cause of delamination in PV modules (which may include corrosion, contamination, gas formation, or process control issues). Specific examination of -adhesion-would likely benefit from a fracture mechanics test method rather than the strength of attachment approach used here.
Initial results suggest the effects of water, which may include plasticization and hydrothermal degradation, are at least comparable to that of UV damage. Weathering studies related to attachment must therefore treat the effect of water before and during aging as well as making sure to control the moisture level before measurement. Pre-conditioning specimens to achieve an internal water concentration beforeweathering or -measurement will extend the overall test duration, but is essential to obtain valid results.

\section{REFERENCES}

[1] D.R. Coulter, E.F. Cuddihy, E.P. Pluedmann, "Chemical Bonding Technology for Terrestrial Photovoltaic Modules", DOE-JPL-1012-91, 1983, pp. 1-65.

[2] J.L. Koenig, F.J. Boerio, E.P. Plueddemann, J. Miller, P.B. Willis, E.F. Cuddihy., Chemical Bonding Technology: Direct Investigation of Interfacial Bonds", DOE/JPL-1012-120, 1986, pp. 1-58.

[3] J.H. Wohlgemuth, T. Silverman, D.C. Miller, P. McNutt, M.D. Kempe and M. Deceglie, "Evaluation of PV Module Field Performance", Proc IEEE PVSC, 2015.

[4] N.G. Dhere, M.B. Pandit, "Study of Delamination in Acceleration Tested PV Modules", Proc. Euro PVSEC, pp. 572575, 2001.

[5] G.J. Jorgensen, T.J. McMahon, "Accelerated and Outdoor Aging Effects on Photovoltaic Module Interfacial Adhesion Properties", PIP, 16, pp. 519-527, 2008.

[6] V. Chapuis, S. Pelisset, M. Raeis-Barneoud, H.-Y. Li, C. Ballif, and L.-E. Perret-Aebi, "Compressive-Shear Adhesion Characterization of PVB and EVA at Different Curing Times Before and After Exposure to Damp-Heat Conditions", PIP, 22 (4), pp. 405-414, 2014.

[7] T.J. McMahon, G.J. Jorgensen, "Adhesion and Thin-Film Module Reliability”, Proc. IEEE World Conf. Energy Conv., pp. 2062-2065, 2006.

[8] "IEC 61730-2 Photovoltaic (PV) module safety qualification Part 2: Requirements for testing," Edition 2, International Electrotechnical Commission: Geneva, 1-57 (2016).

[9] "IEC 61215-2 Terrestrial photovoltaic (PV) modules - design qualification and type approval," Edition 1, International Electrotechnical Commission: Geneva, 1-41(2016).

[10] D.C. Miller, et. al., "Degradation in PV Encapsulation Transmittance: An Interlaboratory Study Towards a ClimateSpecific Test", Proc IEEE PVSC, 2015, 972.

[11] S. Fowler, "Developing steady state exposure conditions in an ASTM G154 fluorescent UV test chamber for backsheet materials," Proc. NREL PVMRW, 2014.

[12] http://atlas-mts.com/online-tools/weather-summary-reports/

[13] A. W. Czanderna and F. J. Pern. "Encapsulation of PV Modules Using Ethylene Vinyl Acetate Copolymer as a Pottant: A Critical Review," SOLMAT, 43, 101-181, 1996.

[14] J.H. Wohlgemuth, P. Hacke, N.S. Bosco, D.C. Miller, M. D. Kempe, S.R. Kurtz, "Assessing the Causes of Encapsulant Delamination in PV Modules", Proc. IEEE PVSC, 2016.

\section{ACKNOWLEDGMENT}

This work was executed by the U.S. Department of Energy under Contract No. DE-AC36-08-GO28308 with the National Renewable Energy Laboratory. Instruments and materials are identified in this paper to describe the experiments. In no case does such identification imply recommendation or endorsement by NIST or NREL. 